\title{
SOJA TRANSGÊNICA VERSUS CONVENCIONAL: ESTIMATIVA DOS CUSTOS OPERACIONAIS DE PRODUÇÃO NA REGIÃO DO MÉDIO PARANAPANEMA, ESTTADO DE SÃO PAULO
}

\author{
Transgenic versus conventional soybean: estimative of the operational production \\ costs in the Middle Paranapanema, São Paulo State
}

\author{
Fernanda de Paiva Badiz Furlaneto ${ }^{1}$, Paulo César Reco ${ }^{2}$, Ricardo Augusto Dias Kanthack ${ }^{3}$, \\ Maura Seiko Tsutsui Esperancini ${ }^{4}$, Andréa Leda Ramos de Oliveira Ojima ${ }^{5}$
}

\begin{abstract}
RESUMO
O estudo estimou o custo operacional de produção da soja convencional e transgênica no Médio Paranapanema, Estado de São Paulo. Foram utilizados resultados de três experimentos de avaliação regional com 19 cultivares de soja, sendo 17 convencionais e 2 transgênicas. As estruturas de custo utilizadas foram custo operacional efetivo (COE) e o custo operacional total (COT). O COT, por hectare, da soja transgênica foi $10,7 \%$ menor que o da soja convencional. Porém, o custo unitário por saca foi menor para a soja convencional em razão da produtividade. A produtividade média foi de 35,2 e de 31,3 para as cultivares convencionais e transgênicas, respectivamente. A maior diferença porcentual no COT ocorreu nos itens "sementes" e "herbicidas". A variação do custo de produção por saca da soja convencional foi de $R \$ 27,7$ a $R \$ 39,5$ e da soja transgênica $R \$ 29,5$ e $R \$ 40,1$. O alto custo dos insumos comprometeu a viabilidade da atividade nos dois sistemas de produção. Há necessidade de continuar a avaliação das cultivares de soja transgênica para conhecer as mais adaptadas regionalmente e tornar mais seguras as indicações técnicas.
\end{abstract}

Termos para indexação: Custo operacional, soja convencional, soja geneticamente modificada.

\begin{abstract}
The study esteemed the operational cost of production of conventional and transgenic soybean in Middle Paranapanema, São Paulo State, Brazil. Results of three experiments of regional evaluation were used with 19 varieties of soybean, being 17 conventional and 2 transgenic ones. The cost structures used were effective operational cost (EOC) and the total operational cost (TOC). The TOC, for hectare, of the transgenic soybean was 10,7\% smaller than the one of the conventional soybean. However, the unitary cost for bag was smaller for the conventional soybean in reason of the productivity. The medium productivity was of 35,2 and of 31,3 bags for hectare for conventional and transgenic ones, respectively. The largest percemtile difference in TOC happened in the items "seeds " and "herbicide". The variation of the production cost for bag of the conventional soybean was from US\$12.8 to US\$18.3 and for the transgenic soybean US\$ 13.7 and US\$ 18.6. The high cost of the inputs committed the viability of the activity in the two production systems. There is need to continue the evaluation of the cultivation of transgenic soybean to know the most adapted ones in the area and to turn safer the technical indications.
\end{abstract}

Index terms: Operational costs, conventional soybean, GM soybean.

(Recebido em 30 de janeiro de 2008 e aprovado em 12 de agosto de 2008)

\section{INTRODUÇÃO}

Nos últimos dez anos, observou-se o aumento do cultivo de plantas transgênicas (MIYAMOTO, 2007). A área mundial de plantas geneticamente modificadas é estimada em 80 milhões de hectares, com destaque especial para a soja com resistência ao herbicida glifosate (soja RR - Roundup Ready), que é a cultura transgênica mais explorada mundialmente, respondendo aproximadamente

'Médica Veterinária, Mestre, Pesquisadora - Departamento de Descentralização do Desenvolvimento/DDD - Secretaria da Agricultura e Abastecimento/ SAA - Agência Paulista de Tecnologia dos Agronegócios/APTA - Rodovia SP 333, Assis/Marília, Km 397 - Cx. P. 263 - $19800-000$ - Assis, SP fernandafurlaneto@apta.sp.gov.br

${ }^{2}$ Engenheiro Agrônomo, Mestre, Pesquisador - Departamento de Descentralização do Desenvolvimento/DDD - Secretaria da Agricultura e Abastecimento/ SAA - Agência Paulista de Tecnologia dos Agronegócios/APTA - Rodovia SP 333, Assis/Marília, Km 397 - Cx. P. 263 - $19800-000$ - Assis, SP fernandafurlaneto@apta.sp.gov.br; reco@apta.sp.gov.br

${ }^{3}$ Engenheiro Agrônomo, Doutor, Pesquisador - Departamento de Descentralização do Desenvolvimento/DDD - Secretaria da Agricultura e Abastecimento/ SAA - Agência Paulista de Tecnologia dos Agronegócios/APTA - Rodovia SP 333, Assis/Marília, Km 397 - Cx. P. 263 - $19800-000$ - Assis, SP kanthack@apta.sp.gov.br

${ }^{4}$ Engenheira Agrônoma, Doutora, Professora - Faculdade de Ciências Agronômicas/FCA - Departamento de Gestão e Tecnologia Agroindustrial/DGTA Universidade Estadual Paulista "Júlio de Mesquita Filho"/UNESP - Rua José Barbosa de Barros, 1780 - Fazenda Lageado - Cx. P. 237 - 18610-307 Botucatu, SP - maura@fca.unesp.br

${ }^{5}$ Engenheira Agrônoma, Mestre, Pesquisadora - Secretaria da Agricultura e Abastecimento/SAA - Instituto de Economia Agrícola/IEA - Avenida Miguel Stéfano, 3900 - Água Funda - 04301-903 - São Paulo, SP - andrea@iea.sp.gov.br 
por $61 \%$ da área global. Na seqüência vem o milho Bt (milho transgênico, contendo genes do Bacillus thuringiensis), o algodão Bt e a canola resistente a herbicidas (ROESSING \& LAZZAROTTO, 2005).

No período de 1996 a 2004, registrou-se um crescimento anual na ordem de $35,70 \%$ da área cultivada com a soja. Atualmente, a comercialização desse tipo de grão, em sua grande maioria, dá-se com materiais geneticamente modificados. Segundo Schnepf et al. (2004), o mercado da soja transgênica teve, até a segunda metade da década de 1990, os Estado Unidos como o principal produtor e, a partir dessa data, o Brasil e a Argentina começaram a se destacar na comercialização mundial.

A soja, que é a principal cultura de grãos do Brasil, tanto em área quanto em produção, respondeu, no ano agrícola 2005/06, por uma produção anual na ordem de 55 milhões de toneladas (CONAB, 2007). De acordo com Miyamoto (2007), estima-se que cerca de $40 \%$ da área total de soja a ser plantada no Brasil, na safra 2007/08, deverá ser de variedades transgênicas.

Dados do Instituto de Economia Agrícola (2006) apontam que no ano de 2006, nos municípios pertencentes ao Escritório de Desenvolvimento Rural de Assis ${ }^{6}$ (EDR), região do Médio Paranapanema, sudoeste do estado de São Paulo, foram semeados 140 mil hectares de soja (14\% da área total de soja cultivada no estado), com uma produção de 344 mil toneladas e produtividade de 2.500 toneladas por hectare. A área cultivada com soja transgênica na safra 2005/06, nos municípios do EDR de Assis, representou cerca de $30 \%$ da área total ocupada com a sojicultura na região. Na safra 2006/07, esse valor foi de aproximadamente $50 \%$.

Em decorrência da tendência de aumento do plantio da soja geneticamente modificada, objetivou-se, neste trabalho, estimar o custo operacional de produção da soja convencional e transgênica no Médio Paranapanema, na região Sudoeste do estado de São Paulo.

\section{MATERIAL E MÉTODOS}

\section{Caracterização dos sistemas de produção}

Na região do Médio Paranapanema, São Paulo, a cultura da soja é desenvolvida através do sistema de plantio direto, predominando a sucessão de cultura soja/milho safrinha, sendo as operações de cultivo mecanizadas.

\footnotetext{
${ }^{6}$ Municípios pertencentes ao EDR de Assis: Assis, Borá, Campos Novos Paulista, Cândido Mota, Cruzália, Echaporã, Florínea, Ibirarema, Lutécia, Maracaí, Palmital, Paraguaçu Paulista, Pedrinhas Paulista, Platina, Quatá e Tarumã.
}

As sementes mais usadas encontram-se no grupo de maturação cultivares precoce (até 120 dias) e semiprecoce (121 a 130 dias). Destacam-se as cultivares no sistema convencional, CD 215, CD 216, CD 208, CD 201, BRS 133, BRS 184 e IAC 18 e, no sistema transgênico, CD213 RR, CD-214 RR e BRS-245 RR.

No cultivo da soja com uso de sementes convencionais, o manejo de plantas daninhas consiste na utilização de produtos com e sem ação residual para uso em pré-emergência e pós-emergência ou produtos como os inibidores da ALS e ACCase, alternativa eficiente e mais segura para o meio ambiente (ROESSING \& LAZZAROTTO, 2005).

No plantio convencional, em média, são necessárias duas ou três aplicações de produtos em mistura, aumentando conseqüentemente o custo com a mão-de-obra e insumos durante o processo produtivo. No cultivo da soja transgênica, a aplicação de glyphosate pósemergente permite controlar as plantas resistentes e, normalmente, é feita apenas uma vez, durante o ciclo de produção da soja.

A aplicação de herbicida pré-emergente nos dois sistemas de plantio é feita em torno de 20 dias antes do plantio e, no máximo, 30 dias após a emergência e evita a perda de produtividade que pode chegar a sete sacas por hectare em decorrência da mato-interferência e da infestação por pragas nos estágios iniciais (GAZZIERO, 2006).

Em áreas altamente infestadas ou com a presença de espécies tolerantes ao glyphosate, são realizadas aplicações seqüenciais de herbicidas, iniciadas aos 15 dias da semeadura, com intervalo de 10 a 15 dias para dose complementar.

A colheita ocorre da primeira quinzena de março à primeira de abril, e normalmente é realizada por empresas terceirizadas, com remuneração do serviço fixa. $\mathrm{O}$ valor cobrado oscila entre 2 a 3 sacas de soja por hectare, com algumas modificações de preço, dependendo da distância, quantidade da área, dificuldade de operação e condições da estrada. $\mathrm{O}$ frete gira em torno de $\mathrm{R} \$ 0,50$ por saca para distância de até $10 \mathrm{~km}$ do local do armazenamento. O rendimento da colhedora varia de 10 a 20 hectares por dia, dependendo da produtividade da lavoura e do tipo de máquina.

\section{Fonte dos dados}

Foram utilizados resultados de três experimentos de avaliação regional instalados nos municípios de Pedrinhas Paulista (LVef) (340m), Cruzália (LVef) (350m) e Palmital (LVdf) (501m) com 19 cultivares de soja, sendo 17 convencionais (A 7001, BRS 133, BRS 184, BRS 232, Carrera, CD 201, CD 202, CD 208, CD 215, CD 216, CD 217, CD 218, Embrapa 48, IAC 18, IAC 23, IAC Foscarin-31, V-Max) e 2 
transgênicas (CD 214 RR e BRS 245 RR). A semeadura ocorreu na segunda quinzena de novembro de 2005, em solo latossolo vermelho eutroférrico, clima moderadamente úmido, com precipitação anual apresentando valores médios de $1.260 \mathrm{~mm}$.

As matrizes dos coeficientes técnicos de produção foram elaboradas com base em informações coletadas junto aos técnicos da Cooperativa dos Cafeicultores da Média Sorocabana (COOPERMOTA), Cooperativa Agropecuária de Pedrinhas Paulista (CAP), Coordenadoria de Assistência Técnica e Extensão Rural (CATI) e produtores rurais, no período de outubro de 2005 a setembro de 2006. Os preços dos materiais, da mão-de-obra e dos serviços foram obtidos em outubro de 2006, nas cidades de Assis, Cândido Mota e Pedrinhas Paulista, no estado de São Paulo. O preço médio de soja recebido pelo produtor na safra 2005/06 foi estimado em $\mathrm{R} \$ 28,00$ por saca de $60 \mathrm{~kg}$ e a cotação do dólar comercial a $\mathrm{R} \$ 2,16$.

\section{Estimativa do custo de produção}

Para a elaboração dos sistemas de produção (MELLO et al., 1998) e matrizes de coeficientes técnicos foram utilizados os seguintes parâmetros coletados em campo: (a) Sistema de Plantio Direto Convencional $(S P D C)$, produtividade esperada de $2.500 \mathrm{~kg} / \mathrm{ha}(41,60$ sacas $60 \mathrm{~kg} / \mathrm{ha}$ ), uso de semente convencional, aplicação seqüencial de herbicidas diferenciados pré e pósemergente; (b) Sistema de Plantio Direto Transgênico (SPDT), produtividade esperada de $2.500 \mathrm{~kg} / \mathrm{ha}$ (41,60 sacas $60 \mathrm{~kg} / \mathrm{ha}$ ), uso de semente transgênica, aplicação única de herbicida pré e pós-emergente.

A metodologia, para estimativa de custos e análise da viabilidade econômica empregada, foi a descrita em Martin et al. (1998): (a) Custo Operacional Efetivo (COE), que constitui a somatória dos custos com a utilização de mão-de-obra, máquinas, equipamentos e insumos; (b) Custo Operacional Total (COT), que resulta da somatória do custo operacional efetivo (COE) e dos custos indiretos monetários ou não monetários, tais como: depreciação de máquinas, equipamentos e benfeitorias, encargos sociais diretos (33\% sobre a mão-de-obra comum e do tratorista), contribuição de seguridade social - CESSR (2,3\% sobre a receita bruta), encargos financeiros $(8,75 \%$ a.a. sobre $50 \%$ do COE) e despesas com assistência técnica ( $2 \%$ sobre o COE). A estimativa dos custos de máquinas e equipamentos seguiu a classificação tradicional de custos fixos e variáveis citada por Hoffmann et al. (1992).

$\mathrm{O}$ ponto de nivelamento, que representa o indicador de custo em relação à unidade do produto, ou seja, determina qual é a produção mínima necessária para cobrir o custo, dado o preço de venda unitário do produto (LAZZARINI NETO, 1995) foi calculado da seguinte maneira:

$$
\mathrm{PN}=\mathrm{COT} / \mathrm{Pu}
$$

onde:

COT $=$ custo operacional total

$\mathrm{Pu}=$ preço unitário do produto

\section{RESULTADOS E DISCUSSÃO}

O custo operacional total (COT) para produção da soja no sistema de plantio direto com utilização de sementes convencionais foi de $\mathrm{R} \$ 1.137,4$ por hectare. A soja cultivada através do sistema de plantio direto e semente transgênica apresentou o custo de produção de R \$ 1.014,9 por hectare, ou seja, o custo total de produção da soja transgênica foi $10,7 \%$ menor do que da soja convencional. Esse porcentual foi semelhante ao apresentado no Agrianual (2007), onde a redução do custo de produção da soja Roundup Ready (RR) foi de $10,6 \%$ no estado de São Paulo.

$\mathrm{O}$ diferencial do custo operacional efetivo (COE), que foi $11,7 \%$ superior no sistema convencional, deve-se ao porcentual relativo gasto com os herbicidas que correspondeu a $16,1 \%$ no sistema convencional e $2,4 \%$ no sistema transgênico (Tabela 1). Os porcentuais do COE, encontrados neste trabalho, equivalem-se aos valores observados por Rocha \& Bemelmans (2004), na safra 2003/ 04, na região de Orlândia, importante região produtora de soja do estado de São Paulo. Esses autores descrevem que o item do custo operacional de produção mais representativo foi o gasto com os materiais consumidos, ou seja, com os insumos utilizados para a condução da lavoura.

Observa-se na Figura 1 que a maior diferença porcentual no custo operacional total (COT) ocorreu nos itens "sementes" e "herbicidas". O preço da semente geneticamente modificada foi, aproximadamente, $40 \%$ superior ao preço da semente convencional em virtude do valor adicional cobrado decorrente dos direito de patente das sementes geneticamente modificadas. Acredita-se, no entanto, que essa diferença de preço tende a diminuir nos próximos anos em decorrência da maior disponibilidade de sementes transgênicas no mercado. $O$ custo com herbicidas no sistema convencional foi superior porque foram realizadas duas aplicações de herbicidas, com combinações de ingredientes ativos para o controle de plantas infestantes.

Medeiros (2004) citou, que o custo com herbicidas no plantio convencional e transgênico no Rio Grande do Sul, safra 2003/04, diferiu em 300\% entre os sistemas. Esses porcentuais variam em decorrência dos herbicidas utilizados (princípio ativo), das espécies de plantas invasoras resistentes e do número de aplicações de herbicidas realizados durante o ciclo produtivo. 
Tabela 1 - Estimativa do custo operacional total da soja, sistema convencional e transgênico na região do Médio Paranapanema, estado de São Paulo, por hectare, safra 2005/06.

\begin{tabular}{|c|c|c|c|c|c|c|}
\hline \multirow{2}{*}{ Item } & \multicolumn{3}{|c|}{ Sistema convencional } & \multicolumn{3}{|c|}{ Sistema transgênico } \\
\hline & $\mathrm{R} \$$ & $\mathrm{COE}$ & $\mathrm{COT}$ & $\mathrm{R} \$$ & $\mathrm{COE}$ & $\mathrm{COT}$ \\
\hline & \multicolumn{4}{|c|}{----- \% ----- } & \multicolumn{2}{|c|}{----- \% ----- } \\
\hline Mão-de-obra & 33,3 & 3,4 & 2,9 & 32,0 & 3,7 & 3,1 \\
\hline Sementes & 100,0 & 10,4 & 8,7 & 130,0 & 15,3 & 12,8 \\
\hline Corretivo & 13,5 & 1,4 & 1,1 & 13,5 & 1,5 & 1,3 \\
\hline Fertilizantes & 177,0 & 18,4 & 15,5 & 177,0 & 20,8 & 17,4 \\
\hline Herbicidas & 154,8 & 16,1 & 13,6 & 20,4 & 2,4 & 2,0 \\
\hline Fungicida & 144,5 & 15,0 & 12,7 & 144,5 & 17,0 & 14,2 \\
\hline Inseticidas & 45,4 & 4,7 & 3,9 & 45,4 & 5,3 & 4,4 \\
\hline Operação de máquinas & 188,0 & 19,5 & 16,5 & 180,9 & 21,3 & 17,8 \\
\hline Empreita $^{1}$ & 104,8 & 10,9 & 9,2 & 104,8 & 12,3 & 10,3 \\
\hline Custo operacional efetivo (COE) & 961,3 & 100,0 & 84,5 & 848,5 & 100,0 & 83,6 \\
\hline Depreciação de máquinas & 79,7 & & 7,0 & 77,6 & & 7,6 \\
\hline Encargos sociais diretos ${ }^{2}$ & 10,9 & & 0,9 & 10,5 & & 1,0 \\
\hline $\mathrm{CESSR}^{3}$ & 24,1 & & 2,1 & 24,1 & & 2,3 \\
\hline Assistência técnica $^{4}$ & 19,2 & & 1,6 & 16,9 & & 1,6 \\
\hline Encargos financeiros $^{5}$ & 42,0 & & 3,7 & 37,1 & & 3,6 \\
\hline Custo operacional total (COT) & 1137,4 & & 100,0 & 1014,9 & & 100,0 \\
\hline Custo operacional total (US\$/ha) & 526,6 & & & 469,8 & & \\
\hline
\end{tabular}

Obs: Cotação do dólar comercial: $\mathrm{R} \$ 2,16$

${ }^{1}$ Refere-se à colheita $(2,5$ sacas $)$ e transporte $(\mathrm{R} \$ 0,50 /$ saca $)$ do produto.

${ }^{2}$ Refere-se à mão-de-obra comum e tratorista (33\%).

${ }^{3}$ Refere-se à contribuição de seguridade social de $2,3 \%$ sobre a receita bruta.

${ }^{4}$ Refere-se a $2 \%$ do $\mathrm{COE}$

${ }^{5}$ Taxa de juros de $8,75 \%$ a.a. sobre $50 \%$ do COE durante o ciclo de produção.

Fonte: Dados de pesquisa.

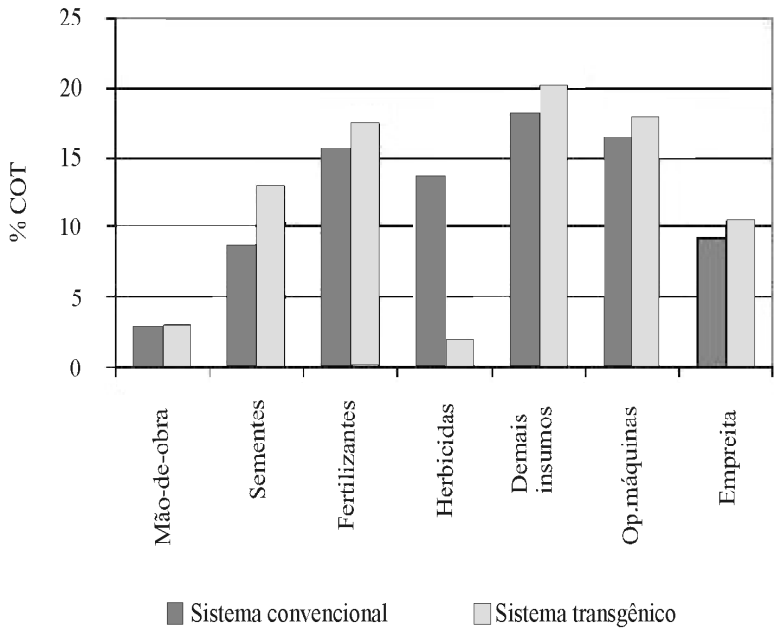

Figura 1 - Comparação entre os porcentuais do custo operacional total (COT) da soja, plantio direto, sistema convencional e transgênico, região do Médio Paranapanema, estado de São Paulo, safra 2005/06. Fonte: Dados de pesquisa.
A produtividade média das cultivares avaliadas oscilou de 41,0 (CD 208) a 28,3 (BRS 245 RR) sacas/ha. Nas variedades CD 208, BRS 133, V-Max, CD 215, CD 202, BRS 184, A 7001, Embrapa 48, CD 201, CD 214 RR observaram-se produtividades estatisticamente semelhantes $(p<0,05)$ entre 41,0 e 34,4 sacas/ha. Considerou-se a produtividade média de 35,2 e de 31,34 para as cultivares convencionais e transgênicas, respectivamente (Tabela 2 ).

A soja transgênica apresentou menor produtividade em relação à soja convencional por ser mais susceptível ao estresse hídrico e a floração ser muito próxima do solo, o que acarreta maiores perdas na colheita em áreas irregulares. Ressalta-se que as variedades de soja são desenvolvidas com base nas características do ambiente onde serão cultivadas. Para tanto, considera-se a disponibilidade de água, o tipo de solo, as doenças e o número de horas de luz, que define o volume de fotossíntese realizado a cada dia. Assim, as 
variedades têm seu ciclo produtivo condicionado à determinada combinação desses fatores e devem ser feitas pesquisas regionais para analisar as variedades mais adaptadas para as condições edafoclimáticas locais (MELGAREJO, 2004).

Pelaez et al. (2004) descrevem que nos dois primeiros anos de introdução da soja transgênica na Argentina, a produtividade foi ligeiramente menor que a convencional, em razão do fato de a nova tecnologia não estar ainda incorporada às variedades de melhor desempenho. Observa-se que esse fato também está ocorrendo no Brasil.

Tabela 2 - Indicadores econômicos da cultura da soja, plantio direto, sistema convencional e transgênico, região do Médio Paranapanema, estado de São Paulo, por hectare, safra 2005/06.

\begin{tabular}{lcc}
\hline \multicolumn{1}{c}{ Cultivar } & Produtividade & $\begin{array}{c}\text { Custo de } \\
\text { produção }\end{array}$ \\
\hline CD 208 & sc/ha & R $\$$ sc \\
BRS 133 & $41,0^{\mathrm{a}}$ & 27,7 \\
V-Max & $40,3^{\mathrm{a}}$ & 28,2 \\
CD 215 & $40,3^{\mathrm{a}-\mathrm{c}}$ & 28,2 \\
CD 202 & $39,6^{\mathrm{a}-\mathrm{c}}$ & 28,7 \\
CD 214 RR* & $39,0^{\mathrm{a}-\mathrm{d}}$ & 29,2 \\
BRS 184 & $34,4^{\mathrm{a}-\mathrm{g}}$ & 29,5 \\
A 7001 & $38,4^{\mathrm{a}-\mathrm{e}}$ & 29,6 \\
Embrapa 48 & $36,7^{\mathrm{a}-\mathrm{f}}$ & 30,9 \\
CD 201 & $36,1^{\mathrm{a}-\mathrm{f}}$ & 31,4 \\
Carrera & $35,2^{\mathrm{a}-\mathrm{g}}$ & 32,3 \\
CD 218 & $33,3^{\mathrm{b}-\mathrm{g}}$ & 34,1 \\
CD 216 & $32,9^{\mathrm{c}-\mathrm{g}}$ & 34,5 \\
CD 217 & $32,9^{\mathrm{c}-\mathrm{g}}$ & 34,5 \\
IAC Foscarin-31 & $31,9^{\mathrm{d}-\mathrm{h}}$ & 35,6 \\
IAC 18 & $31,1^{\mathrm{ch}}$ & 36,5 \\
BRS 232 & $31,0^{\mathrm{f}-\mathrm{h}}$ & 36,7 \\
IAC 23 & $30,0^{\mathrm{f}-\mathrm{h}}$ & 37,9 \\
BRS 245 RR & $28,8^{\mathrm{g}-\mathrm{h}}$ & 39,5 \\
Média & $28,3^{\mathrm{g}-\mathrm{h}}$ & 40,1 \\
CV (\%) & 35,1 & 32,9 \\
Dms (Tukey 5\%) & $7,3^{\mathrm{a}}$ & - \\
\hline
\end{tabular}

* Cultivar transgênica.

Médias seguidas da mesma letra, na coluna, não diferem significativamente entre si pelo teste de Tukey, ao nível de 5\% de probabilidade.

Fonte: Dados de pesquisa.
A variação do custo de produção por saca de soja convencional foi de $\mathrm{R} \$ 27,7$ (CD 208) a $\mathrm{R} \$ 39,5$ (IAC 23). No cultivo da soja geneticamente modificada CD 214 RR e BRS 245 RR, notou-se um custo de produção por saca de $\mathrm{R} \$ 29,5$ e R \$ 40,1, respectivamente. Portanto, o menor custo por saca de soja foi obtido com cultivares convencionais.

$\mathrm{O}$ ponto de nivelamento que determina qual a produção mínima necessária para cobrir o custo operacional de produção, dado o preço de venda unitário do produto, foi de 40,6 e 36,2 sacas por hectare no sistema convencional e transgênico, respectivamente. Portanto, somente a variedade CD 208 (41 sacas por hectare) produziu a quantidade mínima viável para a atividade.

Destaca-se que a cultura da soja, como as demais atividades agrícolas com exploração de grãos, vem apresentando aumento dos custos de produção nos últimos anos na região do Médio Paranapanema, principalmente em decorrência dos gastos com o controle de doenças e pragas advindas da monocultura, em sistemas de sucessão soja/milho safrinha.

\section{CONCLUSÕES}

Na região do Médio Paranapanema, estado de São Paulo, na safra 2005/06, o cultivo da soja no sistema de plantio direto com utilização de sementes transgênicas apresentou o custo operacional total menor do que a semeadura com sementes convencionais. Porém, a produtividade das cultivares de soja Roundup Ready foi inferior ao das convencionais. $\mathrm{O}$ menor custo por saca de soja foi obtido com as cultivares convencionais. Há necessidade de continuar a avaliação das cultivares de soja transgênica para conhecer as mais adaptadas regionalmente e tornar mais seguras as indicações técnicas.

\section{REFERÊNCIAS BIBLIOGRÁFICAS}

AGRIANUAL. Anuário da agricultura brasileira: soja. São Paulo: FNP Consultoria \& Comércio, 2007.

COMPANHIA NACIONAL DE ABASTECIMENTO. Séries históricas safras 1990 a 2006. Disponível em: $\langle$ htttp://www.conab.gov.bri. Acesso em: 1 nov. 2007.

GAZZIERO, D. L. P. Soja transgênica: o que muda no manejo de plantas daninhas. In: CONGRESSO BRASILEIRO DE SOJA, 4., 2006, Londrina, PR. Anais... Brasília, DF: Embrapa, 2006. 156 p.

HOFFMANN, R.; ENGLER, J. J. C.; SERRANO, O.; THAME, A. C. M.; NEVES, E. M. Administração da empresa agrícola.

7. ed. São Paulo: Pioneira, 1992. v. 1, 325 p. 
INSTITUTO DE ECONOMIA AGRÍCOLA. Anuário de informações estatísticas da agricultura: anuário IEA. São Paulo, 2006. 116 p. (Série informações estatísticas da agricultura, 17).

LAZZARINI NETO, S. Controle da produção e custos. São Paulo: SDF, 1995. (Coleção Lucrando com a Pecuária, 9).

MARTIN, N. B.; SERRA, R.; OLIVEIRA, M. D. M.; ANGELO, J. A.; OKAWA, H. Sistema integrado de custos agropecuários - CUSTAGRI. Informações Econômicas, São Paulo, v. 28, n. 1, p. 7-28, jan. 1998.

MEDEIROS, L. Comparativo de custo de produção entre a soja convencional e a soja transgênica na safra 2002/2003 - Rio Brande do Sul. Porto Alegre: UFRGS, 2004. 19 p.

MELGAREJO, L. Análise da evolução da soja transgênica no Rio Grande do Sul. 2004. Disponível em: <http:// 'Www.ecoagencia.com.bil'

MELLO, N. T. C.; ARRUDA, S. T.; CHABARIBERY, D.; CAMARGO, J. R. V.; RIBEIRO JUNIOR, D. Proposta de nova metodologia de custo de produção do Instituto de Economia Agrícola. São Paulo: SAA/IEA, 1988. 13 p. (Relatório de pesquisa, 14/88).
MIYAMOTO, Y. Estimativa da área com soja transgênica no Brasil. Gazeta OnLine, 2007. Disponível em: <http:// iwww.caminhosdocampo.ondarpc.com.bry . Acesso em: 20 nov. 2007 .

PELAEZ, V.; ALBERGONI, L.; GUERRA, M. P. Soja transgênica versus soja convencional: uma análise comparativa de custos e benefícios. Cadernos de Ciência \& Tecnologia, Brasília, v. 21, n. 2, p. 279-309, maio/ago. 2004.

ROCHA, M.; BEMELMANS, P. F. Soja: custo da produção para a safra 2003-04. São Paulo: IEA, 2004. Disponível em: http://www.iea.sp.gov.br/out/verTexto.php?codTexto$1264>$. Acesso em: 20 jun. 2008.

ROESSING, A. C.; LAZZAROTTO, J. J. Soja transgênica no Brasil: situação atual e perspectivas para os próximos anos. In: REUNIÃ̃O DE PESQUISA DE SOJA DA REGIÃO CENTRAL DO BRASIL, 2005, Londrina, PR. Resumos... Londrina: Embrapa, 2005. 578 p.

SCHNEPF, R. D.; DOHLMAN, E.; BOLLING, C. Agriculture in Brazil and Argentina: developments and prospects for major field crops. 2004. Disponível em: <http:// Www.ers.usda.gov/publications/wrs $013>$ : Acesso em: 2 dez. 2007. 